\title{
BMJ Open Time trends, sociodemographic and health factors associated with discharge and length of stay of hospitalised patients with sickle cell disease in Ghana: a retrospective analysis of national routine health database
}

\author{
Clement Tetteh Narh (D) , ${ }^{1,2}$ Joyce Der, ${ }^{1}$ Anthony Ofosu, ${ }^{3}$ Maria Blettner, ${ }^{4}$ \\ Daniel Wollschlaeger ${ }^{4}$
}

To cite: Narh CT, Der J, Ofosu A, et al. Time trends, sociodemographic and health factors associated with discharge and length of stay of hospitalised patients with sickle cell disease in Ghana: a retrospective analysis of national routine health database. BMJ Open 2021;11:e048407. doi:10.1136/ bmjopen-2020-048407

- Prepublication history for this paper is available online To view these files, please visit the journal online (http://dx.doi org/10.1136/bmjopen-2020048407).

Received 26 December 2020 Accepted 15 September 2021

Check for updates

(c) Author(s) (or their employer(s)) 2021. Re-use permitted under CC BY-NC. No commercial re-use. See rights and permissions. Published by BMJ.

For numbered affiliations see end of article.

Correspondence to Dr Clement Tetteh Narh; ctnarh@uhas.edu.gh

\section{ABSTRACT}

Objective Patients with sickle cell disease (SCD) are prone to multiple episodes resulting in frequent hospital visits. We determined the time trends, sociodemographic and health factors associated with length of stay (LoS) for patients with SCD in Ghana.

Design, participants, setting We retrospectively analysed SCD hospitalisation records of 22680 patients from a nationwide database of the Ghana Health Service from 2012 to 2017.

Outcome measures Factors associated with LoS were estimated using Cox regression, while the cumulative incidence of being discharged alive was estimated with in-hospital death as a competing risk.

Results Patients admitted for SCD over 6 years constituted $22680(0.8 \%)$ of nearly 3 million admissions. The median age and LoS for the patients were 16 years (IQR=8-24) and 3 days (IQR=2-4), representing 14202 $(62.6 \%)$ of the patients discharged alive by the third day. Patients with sickle cell anaemia $(6139,52.6 \%)$ with a crisis were more frequent than those without a crisis. Increasing age was associated with shorter LoS when comparing age groups $10-14$ years $(H R=1.08,95 \%$ $\mathrm{Cl} 1.01$ to 1.14$)$ and $25-29$ years $(\mathrm{HR}=1.27,95 \% \mathrm{Cl}$ 1.17 to 1.37 ) to patients aged $0-4$ years. Patients with comorbidities had a longer LoS compared with those without ( $\mathrm{HR}=0.88,95 \% \mathrm{Cl} 0.86$ to 0.90 ).

Conclusion This is the largest study to date documenting factors associated with LoS for patients admitted for SCD. The association of younger age with increased LoS supports recent calls for early SCD screening, especially newborns. The emerging trends and factors accounting for SCD admission require a multisector approach as these patients already experience frequent episodes of pain and hospital visits.

\section{INTRODUCTION}

Global estimates of sickle cell disease (SCD) since 1992 show that it is an important public-health concern in sub-Saharan Africa
Strengths and limitations of this study

- The novelty of this study lies in its large sample size based on a nationwide routine health administrative health records on hospitalised individuals.

- The main strength of this study is it being the first to determine the sociodemographic and health factors associated with length of stay duration hospitalisation of patients with sickle cell disease in all 10 regions of Ghana.

- Although two teaching hospitals and some private hospitals were not included in this analysis, the participating hospitals in this study were representative.

- Multiple records (visits) per person could not be analysed due to the unavailability of unique patient IDs.

(SSA). ${ }^{2}$ SCD is known to have a genetic predisposition, ${ }^{13-6}$ and affects mainly young people ${ }^{4-9}$ with an estimated $50 \%-90 \%$ excess mortality among children in SSA. ${ }^{10} 11$ There is increasing evidence on the prevalence and complications of SCD in Africa, especially Ghana. ${ }^{412} 13$ In tropical African countries, the prevalence of the genetic predisposition was 25\%-30\%. ${ }^{1}$ Specifically, the sickle cell trait prevalence in Ghana is reported to be $25 \%$ with an SCD prevalence of $2 \% .{ }^{14}$ A recent study in the Volta Region of Ghana reported SCD prevalence as $16 \% .^{15}$

Despite increasing knowledge about SCD in Ghana, little is known about the resulting hospital admissions and associated lengths of stay (LoS). Patients diagnosed with SCD often require frequent health facility visits and hospitalisations. ${ }^{16}$ These result from episodes of severe pain, which can reoccur throughout life. ${ }^{51617}$ Patients with SCD suffer a lot more complications from both communicable 
and non-communicable comorbidities. ${ }^{2} 1318$ It is estimated that patients with SCD in the USA made about 2.1 health facility visits per year on average, especially to the emergency department. ${ }^{19}$ Health facilities in lowincome and middle-income countries (LMICs) are inadequately resourced, ${ }^{20}$ which means frequent hospital visits and admissions would harm patients and the hospitals needing to admit them.

An extensive report ${ }^{21}$ indicated a mean LoS during SCD hospital admission of 5 days in the USA. SCD admissions and their direct cost to hospitals have been widely studied in high-income countries where the patient and medical cost records are readily available. ${ }^{21} 22$ In LMICs such as Ghana, there is usually no such national database on patients with SCD care, leading to a lack of empirical evidence. Although the SickleInAfrica consortium has established an SCD registry, ${ }^{23}$ the data contributed is not representative.

So far, the aetiological epidemiological data on admissions and the LoS of patients with SCD in the general population in Ghana has been scarce, not permitting non-biased studies to be carried out. This study analysed new nationwide data which will help to address these research gaps by determining the time trends, sociodemographic and health factors associated with discharge from hospital and LoS for patients admitted for SCD in Ghana. The new data have been provided by the District Health Information Management System II (DHIMS-II) database of the Ghana Health Service (GHS), which enables a nationally representative study. We expected to confirm findings with respect to age structure and risk factors for longer LoS for patients with SCD in Ghana as published in systematic reviews and cross-sectional studies by Grosse et al and Asare et al. ${ }^{10} 16$

\section{METHODS}

\section{Study setting/design/data sources}

This study was carried out in the Republic of Ghana with a population of about 29 million, according to the 2010 Population and Housing Census. At the time of this study, Ghana has 10 administrative regions and 216 districts. ${ }^{24}$ This study used individual visit-level records from the DHIMS-II of the GHS and population data from the Ghana Statistical Service. These records cover all government and some private hospitals in Ghana. To an extent, some tertiary hospitals migrated from regional hospitals to a teaching hospital also contribute data to the DHIMS-II. Currently there are 6 teaching hospitals, 3 university hospitals, 10 regional hospitals, 408 general hospitals, 130 district hospitals, 4 psychiatric hospitals and over 8500 smaller health facilities. Hospitals involved in this study although were self-selected as contributors to the DHIMS-II, they can be considered as representative of each region and district. The DHIMS-II data set included patients with at least one hospitalisation record diagnosed as SCD. ${ }^{25}$ Patient records were anonymised per admission such that multiple admissions from the same patient could not be linked. Following the Strengthening the Reporting of Observational Studies in Epidemiology and REporting of studies Conducted using Observational Routinely-collected Data (RECORD) guidelines ${ }^{26} 27$ for using secondary data from the DHIMS-II database, we analysed 22680 records of hospital admissions due to SCD.

\section{Patient and public involvement}

Not applicable. Patients were not directly involved in this study, except for the use of their previously collected health data on SCD.

\section{Measures}

The hospitalisation data provided by the DHIMS-II mimic the admissions and discharge registers used in the hospitals and contains 14 variables, of which 12 were extracted. These included calendar-year as a continuous covariate while region, sex, age group, occupation, education, health insurance status, surgical procedure and comorbidity were categorical covariates. Of these variables, patient diagnoses are captured as principal and additional diagnoses. Other variables included socio-demographic characteristics, health-related facility factors and the vital status at the end of hospitalisation. Although the DHIMS-II captures other patient-related health data such as health history, diagnostic tests and results and treatment, these were not linked to the hospitalisation data and are not available for this analysis.

\section{Data management}

We assessed data completeness of all extracted variables. Records with missing values for age, sex or date of admission were excluded from the analysis. Duplicate records were identified and dropped based on the complete repetition of the values. In modelling the LoS, we excluded patients with a missing date of discharge as there was no information on LoS after admission since no plausible censoring date could be established.

Both principal and additional diagnoses were identified, coded and categorised according to the WHO International Classification of Diseases, 10th revision, (ICD-10) ${ }^{28}$ For this study, we refer to principal diagnoses as SCD (which is coded as D57.0 for sickle cell anaemia with crisis and D57.1 for sickle cell anaemia without crisis). In the absence of an ICD-10 code in the DHIMS-II database, self-written Stata regular expressions were used in identifying the SCDs for coding and categorisation. We minimised bias by running plausibility and consistency checks for age and sex specific diagnoses and analysis of patterns of missing data. Data management and analysis were performed using Stata V.14.0 (StataCorp).

\section{Statistical analysis}

Descriptive statistics summarised categorical variables using absolute and relative frequencies. For the number of hospitalisations by year, region and age group, we estimated the crude rates based on the projected population of the Ghana Statistical Service. ${ }^{24}$ The primary outcome 


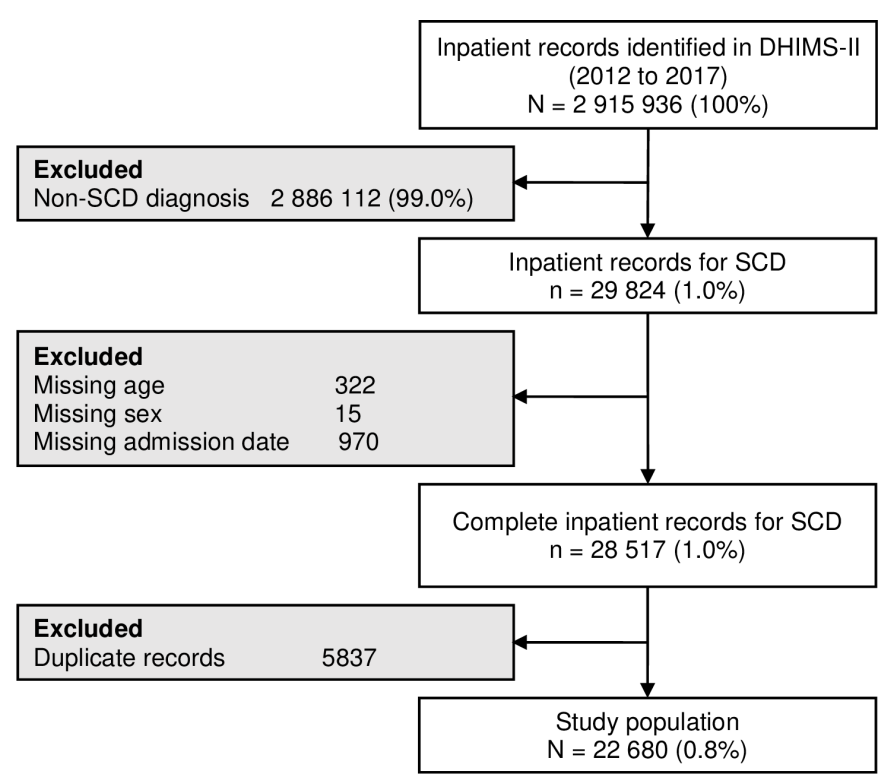

Figure 1 Flowchart of sickle cell disease (SCD) records (2012-2017) from the Ghana Health Service District Health Information Management System (DHIMS-II).

was LoS in the sense of 'time from admission to being discharged alive'. The first analysis used Cox regression for the cause-specific hazard to determine causal influences on LoS. ${ }^{29}$ For this analysis, patients who died in-hospital were censored on their date of death. In order to estimate the cumulative incidence of being discharged alive, we applied a Fine-Gray model with death as a competing risk. ${ }^{30-32}$ These two approaches have in recent years been advocated for an aetiological clinical study such as ours. ${ }^{29-33}$ Both models included calendar-year as a continuous variable and the remaining covariates as categorical variables. In addition, an age-by-sex interaction term allowed for sex-specific age effects. Both models were implemented in Stata stcox, stcrreg and Stcurve. ${ }^{34} \mathrm{We}$ report the $\mathrm{HR}, 95 \% \mathrm{CI}$ and $\mathrm{p}$ values for all associations. HRs above 1 indicate a higher hazard for discharge and thus shorter LoS.

\section{RESULTS}

\section{Data extraction, annual and regional distribution of SCDs}

Patients with SCD accounted for $22680(0.8 \%)$ of all hospitalisation records from 2012 to 2017 (figure 1). There was no obvious temporal trend in the annual crude rates of SCD hospitalisations over the 6-year period, with 5327 admissions in 2016 representing the highest crude rate of $(1.88 / 10000)$, (table 1$)$. Hospitalisation of patients with SCD varied between the 10 regions of Ghana with the Volta and Eastern regions recording the highest (3974 (crude rate $=2.82 / 10000)$ and 4695 (crude rate $=2.71 / 10$ 000), respectively) and the Upper East and Northern regions recording the lowest (416 (crude rate $=0.60 / 10000$ ) and 717 (crude rate $=0.43 / 10000$ ), respectively) rates (table 1 ).

\section{Patients and disease characteristics}

Admissions of patients classified as having SCD with crisis (D57.0) were more frequent than those without crisis (D57.1), (11 675 vs 11 005). The gender distribution in patients with a crisis was nearly the same, while patients without crisis were predominately women (6139 (crude rate $=1.40 / 10$ 000)) versus men (5536 (crude rate $=1.37 / 10$ 000) ) (table 1 and figure 2). Patients aged 15-19 years were the most frequent age group hospitalised for SCD (4106, 18.1\% (crude rate=2.44/10 000)). Patients younger than 15 years represented $44 \%$ of all the SCD hospitalisations. Overall, 15070 (66.5\%) of patients with SCD had some form of formal education. Over onethird of the patients had comorbidities, and nearly 398 $(2 \%)$ died during the hospital stay.

\section{Factors associated with LoS in patients with SCD}

Calendar-year was not associated with hospital length of stay. Patients with SCD hospitalised in the Eastern $(\mathrm{HR}=0.93,95 \%$ CI 0.87 to 0.97 , p value $=0.001)$, Northern $(\mathrm{HR}=0.91,95 \%$ CI 0.85 to 0.98 , $\mathrm{p}$ value $=0.017)$ and the Volta $(\mathrm{HR}=0.92,95 \%$ CI 0.88 to 0.96 , p value $<0.001)$ regions had longer LoS, while patients in the Ashanti $(\mathrm{HR}=1.16,95 \%$ CI 1.10 to 1.23 , p value $<0.001)$, Upper East $(\mathrm{HR}=1.14,95 \%$ CI 1.03 to 1.28 , p value $<0.001)$, Upper West $(\mathrm{HR}=1.14,95 \%$ CI 1.03 to 1.28 , p value $=0.016)$ and Western $(\mathrm{HR}=1.07,95 \%$ CI 1.02 to 1.13 , $\mathrm{p}$ value $=0.007)$ regions had shorter LoS compared with the Greater Accra region. Increasing age was strongly associated with earlier discharge, especially in the age groups 10-14 years $(\mathrm{HR}=1.08,95 \% \mathrm{CI} 1.01$ to 1.14 , p value $<0.001)$ and $25-30$ years $(\mathrm{HR}=1.27,95 \%$ CI 1.17 to 1.37 , p value $<0.001)$ compared with patients aged 0-4 years. Patients aged between 45 and 49 years were the earliest to be discharged $(\mathrm{HR}=1.36,95 \%$ CI 1.15 to 1.62 , $\mathrm{p}$ value $<0.001)$. Gender was not associated with LoS. Patients with comorbidities versus those without $(\mathrm{HR}=0.88,95 \%$ CI 0.86 to $0.90, \mathrm{p}$ value $<0.001)$ and patients who underwent a surgical procedure versus those who did not $(\mathrm{HR}=0.78,95 \% \mathrm{CI}$ 0.69 to 0.87 , $\mathrm{p}$ value $<0.001$ ) during hospitalisation had later discharge (table 2).

We estimated the cumulative incidence function (CIF) of being discharged alive. Due to the age-by-sex interaction term, the CIF can only be displayed for a specific patient group. Figure 3 shows the CIF for the sex and the age group with the highest number of records, considering the competing risk of death. For both men and women aged 15-19years, the cumulative incidence of discharge was nearly $75 \%$ by day 5 and $95 \%$ by day 10 . In both scenarios, women had a higher cumulative incidence of being discharged alive than men.

\section{DISCUSSION}

The GHS is one of the health institutions in the LMICs that invested in improving its routine health data management over the past few decades. ${ }^{35}$ This investment has resulted in high quality data generated from the routine 
Open access

Table 1 Socio-demographic characteristics of patients hospitalised in Ghana stratified by sickle cell disease type, 2012-2017

\section{Sickle cell disease type}

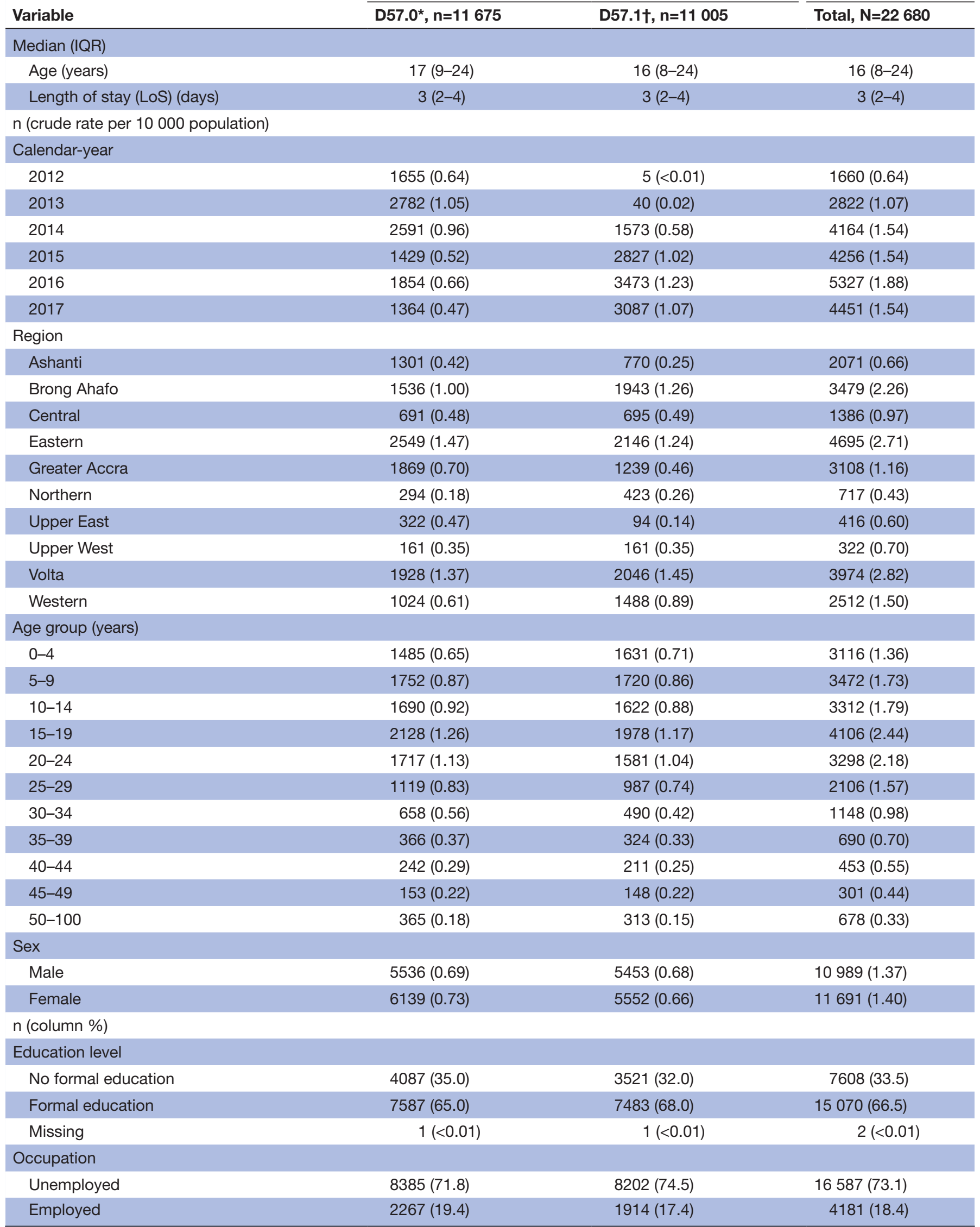

Continued 
Table 1 Continued

\begin{tabular}{|c|c|c|c|}
\hline \multirow[b]{2}{*}{ Variable } & \multicolumn{2}{|c|}{ Sickle cell disease type } & \multirow[b]{2}{*}{ Total, $\mathrm{N}=22680$} \\
\hline & D57.0*, n=11 675 & D57.1†, n=11 005 & \\
\hline Unspecified & $1021(8.8)$ & $889(8.1)$ & $1910(8.4)$ \\
\hline \multicolumn{4}{|c|}{ Insurance status } \\
\hline No & $1500(12.8)$ & $1516(13.8)$ & 3016 (13.3) \\
\hline Missing & $117(1.0)$ & $20(0.2)$ & $137(0.6)$ \\
\hline \multicolumn{4}{|c|}{ Surgical procedure } \\
\hline No & $10778(92.4)$ & $10865(98.7)$ & 21643 (95.4) \\
\hline Yes & $192(1.6)$ & $82(0.8)$ & $274(1.2)$ \\
\hline Missing & $705(6.0)$ & $58(0.5)$ & $763(3.4)$ \\
\hline \multicolumn{4}{|c|}{ Outcome of admission } \\
\hline Alive & 11458 (98.1) & 10800 (98.1) & 22258 (98.1) \\
\hline Died & $202(1.7)$ & $196(1.8)$ & $398(1.8)$ \\
\hline Missing & $15(0.1)$ & $9(0.1)$ & $24(0.1)$ \\
\hline \multicolumn{4}{|l|}{ LoS } \\
\hline $0-3$ days & 7457 (63.9) & $6745(61.3)$ & $14202(62.6)$ \\
\hline 4-7 days & 3022 (25.9) & $2938(26.7)$ & $5960(26.3)$ \\
\hline$>1$ week & $797(6.8)$ & $886(8.1)$ & $1683(7.4)$ \\
\hline Missing & $399(3.4)$ & $436(3.9)$ & $835(3.7)$ \\
\hline
\end{tabular}

*Sickle cell anaemia with crisis.

†Sickle cell anaemia without crisis.

health service provision which is available for administrative and research purposes. Our goal was to determine possible time trends, sociodemographic and health factors associated with hospital LoS for patients admitted for SCD in Ghana.

Based on the WHO ICD-10 broad categories, we categorised SCD into with and without crisis. ${ }^{28}$ In the 6 years analysed, we did not see any obvious time trend in the annual crude rates of hospitalisation. However, the difference between the annual crude rate in 2012 and 2016 was about threefold. The differences in these rates were quite

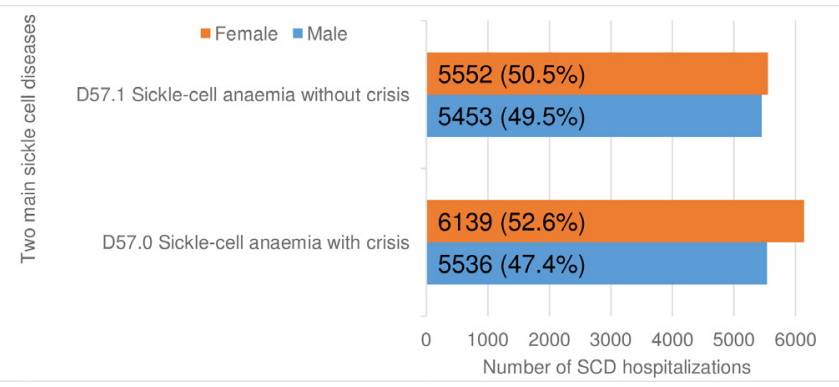

Figure 2 Types of sickle cell disease (SCD) from 2012 to 2017 according to the International Classification of Diseases, 10th revision classification. similar for both hospitalised patients with SCD with or without a crisis. The regional crude rates of hospitalisations varied considerably among the 10 regions of Ghana. The Volta and Eastern regions with moderate projected populations have the highest crude rates of admission, and also had longer LoS compared with the Greater Accra region (reference region). Awaitey et al reported a $17 \%$ prevalence of SCD in the Volta region. ${ }^{15}$ Unsurprisingly, the Upper East and Upper West regions were among the regions with patients that stayed longer during hospitalisation. This is because of the inequity in the distribution of health facilities and resources in Ghana. However, patients in the Ashanti region with more resourced health facilities comparable to the Greater Accra region had the longest hospital stay for patients with SCD. The Ashanti region has contributed to a lot of SCD literature in Ghana for both children and adults.

SCD is generally known to affect very young persons as most of these patients are predisposed genetically. Hence, it was not surprising that we found patients with SCD less than age 15 years to have increasing crude rates of admission which then drop with age. Similarly, increasing age was associated with shorter LoS, with a growing effect until age 30 years and no clear pattern for older age groups. The 
Table 2 The HR and 95\% Cl from the Cox regression model of risk factors for hospitalised sickle cell disease records, 2012-2017

\begin{tabular}{|c|c|c|c|}
\hline Variables & HR & $95 \% \mathrm{Cl}$ & P value \\
\hline Calendar-year (years) & 0.99 & 0.99 to 1.00 & 0.151 \\
\hline \multicolumn{4}{|l|}{ Age group (years) } \\
\hline $0-4$ & ref & & \\
\hline $5-9$ & 0.99 & 0.94 to 1.05 & 0.830 \\
\hline $10-14$ & 1.08 & 1.01 to 1.14 & 0.018 \\
\hline $15-19$ & 1.17 & 1.10 to 1.24 & $<0.001$ \\
\hline $20-24$ & 1.18 & 1.11 to 1.26 & $<0.001$ \\
\hline $25-29$ & 1.27 & 1.17 to 1.37 & $<0.001$ \\
\hline $30-34$ & 1.21 & 1.09 to 1.34 & $<0.001$ \\
\hline $35-39$ & 1.08 & 0.93 to 1.24 & 0.301 \\
\hline $40-44$ & 1.20 & 1.01 to 1.41 & 0.036 \\
\hline $45-49$ & 1.36 & 1.15 to 1.62 & $<0.001$ \\
\hline $50-100$ & 1.11 & 0.98 to 1.26 & 0.107 \\
\hline
\end{tabular}

\begin{tabular}{|lllr|}
\hline Male & ref & & \\
\hline Female & 1.03 & 0.98 to 1.10 & 0.259 \\
\hline $\begin{array}{l}\text { Region } \\
\text { Greater Accra }\end{array}$ & ref & & \\
\hline Ashanti & 1.16 & 1.10 to 1.23 & $<0.001$ \\
\hline Brong Ahafo & 0.96 & 0.92 to 1.01 & 0.099 \\
\hline Central & 0.99 & 0.94 to 1.05 & 0.797 \\
\hline Eastern & 0.93 & 0.89 to 0.97 & 0.001 \\
\hline Northern & 0.91 & 0.85 to 0.98 & 0.017 \\
\hline Upper East & 1.14 & 1.03 to 1.26 & 0.009 \\
\hline Upper West & 1.14 & 1.03 to 1.28 & 0.016 \\
\hline Volta & 0.92 & 0.88 to 0.96 & $<0.001$ \\
\hline Western & 1.07 & 1.02 to 1.13 & 0.007 \\
\hline
\end{tabular}

Employment status

\begin{tabular}{|llll}
\hline Unemployed & ref & & \\
\hline Employed & 1.01 & 0.96 to 1.05 & 0.759 \\
\hline $\begin{array}{l}\text { Unspecified } \\
\text { Education level }\end{array}$ & 0.97 & 0.93 to 1.02 & 0.271 \\
\hline $\begin{array}{l}\text { No formal education } \\
\text { Formal education }\end{array}$ & ref & & \\
\hline $\begin{array}{l}\text { Health insurance ownership } \\
\text { No }\end{array}$ & ref & & \\
\hline Yes & 0.98 & 0.95 to 1.02 & 0.366 \\
\hline Surgical procedure on admission & & \\
\hline No & ref & & \\
\hline Yes & 0.78 & 0.69 to 0.87 & $<0.001$ \\
\hline Comorbidity & & & \\
\hline No & ref & & \\
\hline Yes & 0.88 & 0.86 to 0.90 & $<0.001$ \\
\hline
\end{tabular}

Table 2 Continued

\begin{tabular}{llll}
\hline Variables & HR & $\mathbf{9 5 \%}$ Cl & P value \\
\hline $\begin{array}{c}\text { Age and sex interaction } \\
\text { 0-4 years\#Female }\end{array}$ & ref & & \\
5-9years\#Female & 1.02 & 0.94 to 1.11 & 0.568 \\
10-14 years\#Female & 0.99 & 0.91 to 1.08 & 0.894 \\
15-19years\#Female & 1.03 & 0.95 to 1.12 & 0.406 \\
20-24 years\#Female & 0.96 & 0.88 to 1.05 & 0.396 \\
25-29years\#Female & 0.88 & 0.80 to 0.98 & 0.017 \\
30-34 years\#Female & 0.90 & 0.79 to 1.03 & 0.116 \\
35-39years\#Female & 0.96 & 0.81 to 1.14 & 0.653 \\
40-44 years\#Female & 0.93 & 0.76 to 1.14 & 0.489 \\
45-49years\#Female & 0.88 & 0.70 to 1.10 & 0.251 \\
50-100years\#Female & 0.89 & 0.76 to 1.04 & 0.148 \\
\hline
\end{tabular}

large cohort of young patients with SCD being hospitalised could be explained by the dominance of this age group among patients with SCD which is reflected in several SCD cross-sectional studies reviewed by Grosse $e t a l^{10}$ a systematic review and cross-sectional studies by Owusu $e t a l^{3637}$ and another cross-sectional study in Uganda by Ndeezi et al..$^{38}$ Hospitalisation and LoS were dominated by women, which is consistent with smaller studies conducted in Ghana and elsewhere, ${ }^{16}$ 39-41 although some studies reported more men. ${ }^{42} 43$

Patients in over two-thirds of the hospitalisation records analysed had some kind of formal education. Although education was not associated with LoS, we believe that considering the median age of these patients, hospitalisations due to SCD would be a major disruption in their schooling calendar. This phenomenon could further be explained by the fact that the median age of our study population was 16years, the age at which most of the Ghanaian population is in Senior High or a Vocational

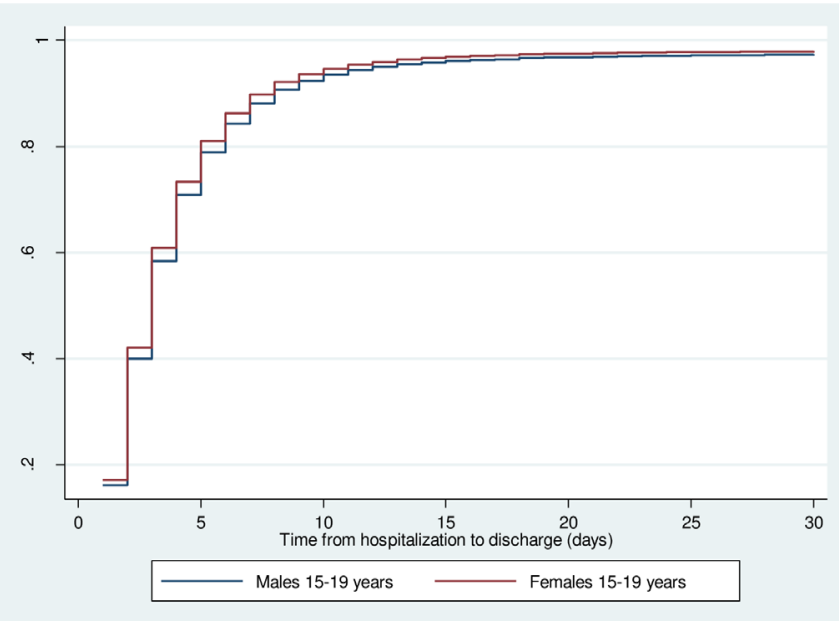

Figure 3 Cumulative incidence function of discharge among hospitalised patients with sickle cell disease, taking into account the competing risk of death. 
Technical School. ${ }^{39}$ Therefore, paying closer attention to outpatient management of patients with SCD could help reduce school absenteeism. Patients hospitalised for SCD with comorbidities and patients who had a surgical procedure during admission were more likely to be discharged later compared with those without comorbidity or did not undergo any surgical procedure. The plausible explanation for this finding could imply that the main reason for hospitalisation might not necessarily be SCD as patients with SCD are more vulnerable to other conditions such as infectious and non-infectious diseases. A considerable literature on these comorbidities has been published both locally and internationally. ${ }^{20} 36-394344$ The strong association of comorbidities with SCD has two implications: first, patients should have the opportunity to take preventive measures against other diseases. Second, public health education and hospital management of patients with SCD should be tailored towards comorbidities within a particular region or area due to the regional effects on hospitalisation. Also, the fact that the admitted patients with SCD who underwent a surgical procedure were discharged later than those who did not undergo any surgical procedure could imply that the condition requiring surgery necessitated hospitalisation.

The interpretability and generalisability of the results in this study are subject to certain limitations. Two premier teaching hospitals in Ghana do not contribute data to the DHIMS-II database due to their autonomy. Also, the DHIMS-II does not cover all private hospitals. However, the number of persons treated in these teaching and private hospitals are small and do not affect very much the overall results. Our study did not include information on other risk factors such as patient health history, diagnostic tests and treatment. Other limitations in this study that could have affected the hospitalisation rates and LoS of patients with SCD include that each admission was treated as a unique record. Therefore, the extracted data could not be linked to individual patients to determine multiple visits. Finally, in order to minimise the bias that might be introduced in statistical models' due to multiple admissions of the same patient, we specified the sandwich estimator for the residual variance making the results robust to non-independence of observations. Furthermore, hospitalisation for a disease depends on several factors, implying that our hospitalisation estimates do not directly reflect disease incidence or prevalence. A survival related bias might have been introduced since our study only included patients with SCD who survived long enough to receive medical care in a hospital. In spite of its limitations, the study adds to our aetiological understanding of the patients with SCD requiring hospitalisation in Ghana.

\section{CONCLUSION}

Despite its exploratory nature, this nationwide study in Ghana offers insight into the factors associated with hospital LoS for patients admitted for SCD. There were no obvious temporal trends in crude hospitalisation rates, however, some unexplained spikes were noticed especially in 2016.
Hence, the provision of focused resources and education on significant factors such as comorbidities and surgery during admission will enhance the health of patients with SCD and reduce hospitalisations. In addition to the frequent episodes of pain and hospital visits experienced by patients with SCD. These factors are multifaceted, which require a multisector approach to secondary and tertiary preventions. The impact of these could not be overlooked, as they have dire consequences for individuals, families and the country. Ensuring appropriate health systems, services, support and public health education for patients with SCD should be a priority for stakeholders.

\section{Author affiliations}

${ }^{1}$ Epidemiology and Biostatistics, School of Public Health, University of Health and Allied Sciences, Hohoe, Volta Region, Ghana

${ }^{2}$ Biostatistics, Johannes-Gutenberg Universitat Mainz Institut für Medizinische Biometrie Epidemiologie und Informatik, Mainz, Rheinland-Pfalz, Germany ${ }^{3}$ Policy, Planning, Monitoring and Evaluation Division (PPMED), Ghana Health Service, Accra, Greater Accra, Ghana

${ }^{4}$ Radiation Epidemiology, Johannes-Gutenberg Universitat Mainz Institut für Medizinische Biometrie Epidemiologie und Informatik, Mainz, Rheinland-Pfalz, Germany

Acknowledgements We acknowledge the Ghana Health Service for providing us with the patient hospitalisation data.

Contributors CTN and MB conceptualised the idea for the study. CTN, MB and DW contributed to designing the study supervised by MB and DW. CTN, AO and JD contributed to data extraction and cleaning. CTN and DW performed the analyses and interpreted the data supervised by MB. CTN, JD, AO, MB and DW wrote and revised the manuscript. All authors read and approved the final manuscript.

Funding The first author was supported by a scholarship from the DAAD and the Government of Ghana, and the Mainzer Vereins zur Förderung der Epidemiologie, Biometrie, Informatik und der Krebsregister e.V. (VEBIK). This paper fulfils part of the requirements of CTN's PhD.

Competing interests None declared.

Patient and public involvement Patients and/or the public were not involved in the design, or conduct, or reporting, or dissemination plans of this research.

Patient consent for publication Not applicable.

Ethics approval This study received ethical approval from the Ghana Health Service Ethics Review Committee (GHS-ERC: 002/12/17) as part of the first author's $\mathrm{PhD}$ thesis.

Provenance and peer review Not commissioned; externally peer reviewed.

Data availability statement Data are available upon reasonable request. All data relevant to the study are included in the article or uploaded as supplementary information. Data used in this study would be published with the manuscript. Extra data is available by emailing the first author.

Open access This is an open access article distributed in accordance with the Creative Commons Attribution Non Commercial (CC BY-NC 4.0) license, which permits others to distribute, remix, adapt, build upon this work non-commercially, and license their derivative works on different terms, provided the original work is properly cited, appropriate credit is given, any changes made indicated, and the use is non-commercial. See: http://creativecommons.org/licenses/by-nc/4.0/.

ORCID iD

Clement Tetteh Narh http://orcid.org/0000-0002-4025-5433

\section{REFERENCES}

1 Modell B, Darlison M. Global epidemiology of haemoglobin disorders and derived service indicators. Bull World Health Organ 2008;86:480-7

2 Ware RE, de Montalembert M, Tshilolo L, et al. Sickle cell disease. The Lancet 2017;390:311-23. 
3 Anie KA, Egunjobi FE, Akinyanju OO. Psychosocial impact of sickle cell disorder: perspectives from a Nigerian setting. Global Health 2010;6:2.

4 Makani J, Cox SE, Soka D, et al. Mortality in sickle cell anemia in Africa: a prospective cohort study in Tanzania. PLoS One 2011;6:e14699.

5 Stuart MJ, Nagel RL. Sickle-Cell disease. Lancet 2004;364:1343-60.

6 Weatherall DJ. The challenge of haemoglobinopathies in resourcepoor countries. Br J Haematol 2011;154:736-44.

7 Aygun B, Odame I. A global perspective on sickle cell disease. Pediatr Blood Cancer 2012;59:386-90.

8 Bain BJ. Neonatal/newborn haemoglobinopathy screening in Europe and Africa. J Clin Pathol 2009;62:53-6.

9 Dennis-Antwi J, Dyson S, Ohene-Frempong K. Healthcare provision for sickle cell disease in Ghana: challenges for the African context. Diversity in Health and Social Care 2008;5:241-54.

10 Grosse SD, Odame I, Atrash HK, et al. Sickle cell disease in Africa: a neglected cause of early childhood mortality. Am J Prev Med 2011;41:S398-405.

11 Wastnedge E, Waters D, Patel S, et al. The global burden of sickle cell disease in children under five years of age: a systematic review and meta-analysis. J Glob Health 2018;8:021103.

12 Diallo DA, Guindo A. Sickle cell disease in sub-Saharan Africa: stakes and strategies for control of the disease. Curr Opin Hematol 2014;21:210-4.

13 Wonkam A, Ponde C, Nicholson N, et al. The burden of sickle cell disease in Cape town. S Afr Med J 2012;102:752-4.

14 Ohene-Frempong K, Oduro J, Tetteh $\mathrm{H}$, et al. Screening newborns for sickle cell disease in Ghana: table 1. Pediatrics 2008;121:S120.2-1.

15 Awaitey DK, Akorsu EE, Allotey EA, et al. Assessment of hemoglobin variants in patients receiving health care at the $\mathrm{HO}$ teaching hospital: a three-year retrospective study. Adv Hematol 2020;2020:1-6.

16 Asare EV, Wilson I, Benneh-Akwasi Kuma AA, et al. Burden of sickle cell disease in Ghana: the Korle-Bu experience. Adv Hematol 2018;2018:1-5

17 Rees DC, Williams TN, Gladwin MT. Sickle-Cell disease. Lancet 2010;376:2018-31.

18 Platt OS, Brambilla DJ, Rosse WF, et al. Mortality in sickle cell disease. life expectancy and risk factors for early death. $N$ Engl J Med 1994;330:1639-44.

19 Paulukonis ST, Feuchtbaum LB, Coates TD, et al. Emergency department utilization by Californians with sickle cell disease, 20052014. Pediatr Blood Cancer 2017;64:e26390.

20 Ansong D, Akoto AO, Ocloo D, et al. Sickle cell disease: management options and challenges in developing countries. Mediterr J Hematol Infect Dis 2013;5:e2013062.

21 Databases H. Healthcare cost and utilization project (HCUP). HCUP nationwide inpatient sample (NIS) healthcare cost and utilization project (HCUP) 1988-2009. Rockville, MD: Agency for Healthcare Research and Quality, 2013.

22 Kunz JB, Lobitz S, Grosse R, et al. Sickle cell disease in Germany: results from a national registry. Pediatr Blood Cancer 2020;67:e28130.

23 Munung NS, Nembaware V, de Vries J, et al. Establishing a MultiCountry sickle cell disease registry in Africa: ethical considerations. Front Genet 2019;10:943.

24 Ghana Statistical Service. 2010 population and housing census report: Ghana statistical service, 2014.

25 Adaletey DL, Jolliffe B, Braa J. Peer-performance review as a strategy for strengthening health in-formation systems: a case study from Ghana. Journal of Health Informatics in Africa 2014;2.
26 Benchimol El, Smeeth L, Guttmann A, et al. The reporting of studies conducted using observational Routinely-collected health data (record) statement. PLoS Med 2015;12:e1001885

27 von Elm E, Altman DG, Egger M, et al. The strengthening the reporting of observational studies in epidemiology (STROBE) statement: guidelines for reporting observational studies. Ann Intern Med 2007;147:573-7.

28 World Health Organization. International statistical classification of diseases and related health problems. World Health Organization, 2004.

29 Noordzij M, Leffondré K, van Stralen KJ, et al. When do we need competing risks methods for survival analysis in nephrology? Nephrol Dial Transplant 2013;28:2670-7.

30 Austin PC, Lee DS, Fine JP. Introduction to the analysis of survival data in the presence of competing risks. Circulation 2016;133:601-9.

31 Brock GN, Barnes C, Ramirez JA, et al. How to handle mortality when investigating length of hospital stay and time to clinical stability. BMC Med Res Methodol 2011;11:144.

32 Wolbers M, Koller MT, Stel VS, et al. Competing risks analyses: objectives and approaches. Eur Heart J 2014;35:2936-41.

33 Tripepi G, Jager KJ, Dekker FW, et al. Testing for causality and prognosis: etiological and prognostic models. Kidney Int 2008;74:1512-5.

34 Fine JP, Gray RJ. A proportional hazards model for the Subdistribution of a competing risk. J Am Stat Assoc 1999:94:496-509.

35 Poppe O, Jolliffe B, Adaletey DL. Cloud computing for health information in Africa? Comparing the case of Ghana to Kenya. Journal of Health Informatics in Africa 2013;1.

36 Owusu EDA, Visser BJ, Nagel IM, et al. The interaction between sickle cell disease and HIV infection: a systematic review. Clin Infect Dis 2015;60:612-26.

37 Owusu EDA, Brown CA, Grobusch MP, et al. Prevalence of Plasmodium falciparum and non-P. falciparum infections in a highland district in Ghana, and the influence of HIV and sickle cell disease. Malar J 2017;16:167.

38 Ndeezi G, Kiyaga C, Hernandez AG, et al. Burden of sickle cell trait and disease in the Uganda sickle surveillance study (US3): a crosssectional study. Lancet Glob Health 2016;4:e195-200.

39 Adzika VA, Glozah FN, Ayim-Aboagye D, et al. Socio-Demographic characteristics and psychosocial consequences of sickle cell disease: the case of patients in a public hospital in Ghana. J Health Popul Nutr 2017;36:4

40 Antwi-Boasiako C, Ekem I, Abdul-Rahman M, et al. Hematological parameters in Ghanaian sickle cell disease patients. J Blood Med 2018;9:203-9.

41 Steele C, Sinski A, Asibey J, et al. Point-Of-Care screening for sickle cell disease in low-resource settings: a multi-center evaluation of HemoTypeSC, a novel rapid test. Am J Hematol 2019;94:39-45.

42 Aljuburi G, Laverty AA, Green SA, et al. Trends in hospital admissions for sickle cell disease in England, 2001/02-2009/10. J Public Health 2012;34:570-6

43 Anto EO, Obirikorang C, Acheampong E, et al. Renal abnormalities among children with sickle cell conditions in highly resource-limited setting in Ghana. PLoS One 2019;14:e0225310.

44 Ephraim RKD, Osakunor DNM, Cudjoe O, et al. Chronic kidney disease is common in sickle cell disease: a cross-sectional study in the Tema Metropolis, Ghana. BMC Nephrol 2015;16:75. 